\title{
REMARKS ON THE NAME OF THE HADROSAUROID DINOSAUR EOLAMBIA CAROLJONESA KIRKLAND, 1998 (ORNITHISCHIA)
}

\author{
THIAGO VERNASCHI V. COSTA \\ Instituto de Recursos Naturais, Universidade Federal de Itajubá, Av. BPS, 1303, Pinheirinho, Itajubá, MG, Brasil. \\ tvvcosta@gmail.com
}

\begin{abstract}
The large hadrosauroid dinosaur Eolambia caroljonesa was named in honor of Carol Jones, the discoverer of the place where the type specimens were found. However, according to the article 31.1.2 of the ICZN, the form caroljonesae should have been used and, thus, caroljonesa represents an incorrect original spelling subject to a justified emendation. Such emendation is required in cases on which the incorrect original spelling of a species-group name must be corrected, as stated by the article 32.5.1 of the ICZN. Therefore, based on the express application of the nomenclatural rules, the name of the species must be corrected to Eolambia caroljonesae.
\end{abstract}

Keywords: nomenclature, ICZN, Eolambia caroljonesa, Ornithischia, Hadrosauroidea.

Eolambia caroljonesa Kirkland, 1998 is a large hadrosauroid dinosaur from the Upper Cretaceous of the United States, described based on specimens from the Cedar Mountain Formation, Utah State (Kirkland, 1998). The species is known by copious fossil material, including adult and juvenile skeletal remains, eggshell fragments, and tracks, indicating that it was one of the most abundant large herbivores of the Upper Cretaceous of Southwestern United States (Kirkland, 1998). It was originally described as a basal member of Hadrosauridae, but subsequent studies found it to be a basal hadrosauroid outside of that family (Head, 2001; Normand 2002; Normand, 2004; McDonald et al., 2010). The holotype and paratypes, all disarticulated partial skeletons, are housed at the College of Eastern Utah Prehistoric Museum, Price, Utah, and Oklahoma Museum of Natural History, Norman, Oklahoma.

The species was first known as Eohadrosaurus caroljonesi in Kirkland (1997, p. 99), a name introduced in a book chapter without an appropriate description that therefore became a nomen nudum under the rules of the International Code of Zoological Nomenclature (ICZN 1999). For this reason, a valid new genus name was proposed for that taxon in the following year by Kirkland (1998), Eolambia caroljonesa. In that description, the author stated that the specific name was in tribute to Carol Jones, who discovered the site where the specimens have been found. The name Eolambia caroljonesa has been in use in the literature ever since (Head, 2001; Bolotsky \& Godefroit, 2004; Horner et al., 2004; Normand, 2004; Garrison et al., 2007; Prieto-Márquez, 2010; McDonald et al., 2010; Paul, 2010, 2016; Wang et al., 2011; McDonald et al., 2012; Prieto-Márquez et al., 2016; Carpenter \& Cifelli, 2016; McDonald et al., 2017).

In this paper, I review the nomenclature of the species based on the express application of the nomenclatural rules. According to the Article 31.1 of the ICZN (1999), "A species-group name formed from a personal name may be either a noun in the genitive case, or a noun in apposition (in the nominative case), or an adjective or participle". The fact of the species had been named as E. caroljonesi (even as a nomen nudum) and subsequently as $E$. caroljonesa, as stated in Kirkland (1998), undoubtedly indicates the author's intention in forming a name in the genitive case. However, according to the same article of the Code (31.1.2), speciesgroup names based on personal names in the genitive case must be formed by adding the stem of the name to a standard ending, as follows: "A species-group name, if a noun in the genitive case (see Article 11.9.1.3) formed directly from a modern personal name, is to be formed by adding to the stem of that name - $i$ if the personal name is that of a man, -orum if of men or of man (men) and woman (women) together, -ae if of a woman, and-arum if of women; the stem of such a name is determined by the action of the original author when forming the genitive."(bold emphasis mine). Hence, as the species was named after Carol Jones, a woman, the form caroljonesae should have been used and, thus, caroljonesa represents an incorrect original spelling subject to a justified emendation. Such emendation is required in cases on which the incorrect original spelling of a species-group name must be corrected, as stated by the article 32.5.1 of the Code, as follows: "If there is in the original publication itself, without recourse to any external source of information, clear evidence of an inadvertent error, such as a lapsus calami or a copyist's or printer's error, it must be corrected'. Therefore, based on the articles 31.1.2 and 32.5.1 of the Code, the name Eolambia caroljonesa is an incorrect original spelling that must be corrected to Eolambia caroljonesae. 


\section{ACKNOWLEDGEMENTS}

I am indebted to the National Council for Scientific and Technological Development (CNPq) for the postdoctoral fellowship (Proc. 150722/2017-6), and to two anonymous reviewers for the valuable comments on the submitted manuscript.

\section{REFERENCES}

Bolotsky, Y.L. \& Godefroit, P. 2004. A new hadrosaurine dinosaur from the late Cretaceous of far Eastern Russia. Journal of Vertebrate Paleontology, 24:351-365. doi:10.1671/1110

Carpenter, K. \& Cifelli, R.L. 2016. A possible juvenile ceratopsoid ilium from the Cenomanian of central Utah, USA. Cretaceous Research, 60:167-175. doi:10.1016/j.cretres.2015.11.016

Garrison, J.R.; Brinkman, D.; Nichols, D.J.; Layer, P.; Burge, D. \& Thayn, D. 2007. A multidisciplinar study of the Lower Cretaceous Cedar Mountain Formation, Mussentuchit Wash, Utah: a determination of the paleoenvironment and paleoecology of the Eolambia caroljonesa dinosaur quarry. Cretaceous Research, 28:461-494. doi:10.1016/j.cretres.2006.07.007

Head, J.J. 2001. A reanalysis of the phylogenetic position of Eolambia caroljonesa (Dinosauria, Iguanodontia). Journal of Vertebrate Paleontology, 21:392-396. doi:10.1671/02724634(2001)021[0392:AROTPP]2.0.CO;2

Horner, J.R.; Weishampel, D.B. \& Forster, C.A. 2004. Hadrosauridae. In: D.B. Weishampel; P. Dodson \& H. Osmólska (eds.) The Dinosauria, University of California Press, p. 438-463.

ICZN. 1999. International Code of Zoological Nomenclature. $4^{\text {th }} \mathrm{ed}$. London, The International Trust for Zoological Nomenclature, $306 \mathrm{p}$.

Kirkland, J.I. 1997. Cedar Mountain Formation. In: P.J. Currie \& K. Padian (eds.) Encyclopedia of Dinosaurs, Academic Press, p. 98-99.

Kirkland, J.I. 1998. A new hadrosaurid from the upper Cedar Mountain Formation (Albian-Cenomanian: Cretaceous) of eastern Utah - the oldest known hadrosaurid (lambeosaurine?). In: S.G. Lucas; J.I. Kirkland \& J.W. Estep (eds.) Lower and Middle Cretaceous terrestrial ecosystems, Albuquerque, New Mexico Museum of Natural History and Science, p. 283-296 (Bulletin 14).
McDonald, A.T.; Bird, J.; Kirkland, J.I. \& Dodson, P. 2012. Osteology of the basal Hadrosauroid Eolambia caroljonesa (Dinosauria: Ornithopoda) from the Cedar Mountain Formation of Utah. PLoS ONE, 7:e45712.

doi:10.1371/journal.pone.0045712

McDonald, A.T.; Gates, T.A.; Zanno, L.E. \& Makovicky, P.J. 2017. Anatomy, taphonomy, and phylogenetic implications of a new specimen of Eolambia caroljonesa (Dinosauria: Ornithopoda) from the Cedar Mountain Formation, Utah, USA. PLoS ONE, 12:e176896. doi:10.1371/journal.pone.0176896

McDonald, A.T.; Kirkland, J.I.; DeBlieux, D.D.; Madsen, S.K.; Cavin, J.; Milner, A.R.C. \& Panzarin, L. 2010. New basal iguanodonts from the Cedar Mountain Formation of Utah and the evolution of the Thumb-Spiked dinosaurs. PLoS ONE, 5:e14075. doi:10.1371/journal.pone.0014075

Normand, D.B. 2004. Iguanodontia. In: D.B. Weishampel; P. Dodson \& H. Osmólska (eds.) The Dinosauria, University of California Press, p. 413-437.

Paul, G.S. 2010. The Princeton field guide to dinosaurs. $1^{\text {st }} \mathrm{ed}$. New Jersey, Princeton University Press, $321 \mathrm{p}$.

Paul, G.S. 2016. The Princeton field guide to dinosaurs. $2^{\text {nd }}$ ed. New Jersey, Princeton University Press, 362 p.

Prieto-Márquez, A. 2010. Global historical biogeography of hadrosaurid dinosaurs. Zoological Journal of the Linnean Society, 159:503-525. doi:10.1111/j.1096-3642.2010.00642.x

Prieto-Márquez, A.; Erickson, G.M. \& Ebersole, J.A. 2016. A primitive hadrosaurid from southeastern North America and the origin and early evolution of duck-billed dinosaurs. Journal of Vertebrate Paleontology, 36:e1054495. doi:10.1080/0272463 4.2015.1054495

Wang, X.; Pan, R.; Butler, R. \& Barrett, P.M. 2011. The postcranial skeleton of the iguanodontian ornithopod Jinzhousaurus yangi from the Lower Cretaceous Yixian Formation of western Liaoning, China. Earth and Environmental Science Transactions of the Royal Society of Edinburgh, 101:135-159. doi:10.1017/ S1755691010009266

Received in 05 December, 2018; accepted in 30 June, 2019. 